Dhaka Univ. J. Biol. Sci. 26(2): 133-140, 2017 (July)

\title{
FACTORS INFLUENCING PERCEIVED COMMUNITY CONNECTEDNESS AMONG UNIVERSITY STUDENTS
}

\author{
Tammat Binte Mizan and Md Azharul Islam* \\ Department of Educational and Counselling Psychology, \\ University of Dhaka, Dhaka-1000, Bangladesh
}

Key words: Community connectedness, Internet addiction, Depression, Young adults

\begin{abstract}
A large body of research shows that individual's perceived sense of connectedness with his or her community has a robust association with health, well-being, and productivity. However, little is known about the factors that might influence one's community connectedness (CC). Three hundred university students from three higher education institutes responded to a selfadministered questionnaire that included demographic, behavioural and psychological measures such as (i) perceived community connectedness, (ii) depression and (iii) Internet addiction. Results revealed that there was a significant positive association of CC with age, number of siblings and SES and a significant negative association with Internet addiction and depression. Multiple regression found age, socio-economic status (SES), Internet addiction and level of depression were the significant factors influencing participants' CC $\left[F(7,292)=26.406, p<.001\right.$, Adj. $\left.R^{2}=0.373\right]$. Findings are discussed in the light of existing literature.
\end{abstract}

\section{Introduction}

Community connectedness (CC) is a psychological sense of belonging; experiencing a sense of closeness with others in the community ${ }^{(1)}$. It can be defined as 'the convergence of individuals' desires to belong to a larger collective, establish a mutually influential relationship with that collective, satisfy their individual needs and be rewarded through their collective affiliation, and construct a shared emotional connection(2). People who are more socially connected report less psychological distress, including depression and low self-esteem, than the less connected individuals ${ }^{(3)}$. Thus, the more socially connected a person felt, the better he or she perceived himself or herself as physically and mentally healthy.

Perceived CC can be characterized by the subjective experience of one's feelings of connectedness and belongingness with the community. The degree to which one perceives himself or herself as connected to the community is informed by personality and other individual-level characteristics and cognitive schemas ${ }^{(3)}$. Perceived connectedness has been linked to physical and mental health, an observation evidenced by both

*Author for correspondence: <azharulislam@du.ac.bd>. 
sociological and psychological research ${ }^{(3)}$. For example, a large body of research has demonstrated a robust association between disconnectedness and worse health, including cardiovascular disease, inflammation, and depression ${ }^{(3)}$. Socially connected individuals may receive support from community members, which may assist them in active coping and help to reduce stress. On the other hand, people who are less connected may have perceived isolation which may affect their physical health given that its well-established link with mental health ${ }^{(4)}$.

The current global technological advancement has resulted in an increasing downward trend in relation to $\mathrm{CC}$, especially within the young groups. Identifying modifiable factors believed to be associated with perceived CC is, therefore, a critical agendum for psychological research. Existing literature shows that technological transformation of leisure, the growth of cable and satellite system, and the addiction to virtual reality serve to isolate the individual from the community group ${ }^{(5)}$. Another study indicates that social interactions and perceived connectedness vary between genders. Low social network involvement is reported by older men, whereas low perceived social support is reported by older women ${ }^{(6)}$. Again, age is arguably positively related to the experience of loneliness ${ }^{(7)}$. It has been found to be negatively related to network size, closeness to network members, and the number of non-primary-group ties ${ }^{(8)}$. In contrast, some evidence revealed that with age individual develops the civic sense and feel the need to participate in civic life ${ }^{(9)}$. Thus they become more connected with their community.

Psychological conditions such as Internet addiction and depression could also appear as influential factors in relation to perceived CC. Internet addiction or problematic use is one of the individuals and social problems of Internet overusing ${ }^{(10)}$. A national survey in the United States reported that $93 \%$ of young people use the Internet at least occasionally and $95 \%$ of all teenagers ages between 12 and 17 years remain online ${ }^{(11)}$. In Bangladesh, Internet users have increased tremendously resulting $6.5 \%$ of the entire population encompass access to the Internet ${ }^{(12)}$. In general, people who spent more time on the Internet are less likely to make social connections. Limited face-to-face interaction can gradually lead to a disconnection from the community which eventually might result in isolation, loneliness, and depression ${ }^{(10)}$. A recent study with the graduate students of Bangladesh reported that around $24 \%$ of the participants reported experiencing addiction to the Internet ${ }^{(13)}$ characterized by higher psychological distress.

In addition to Internet addiction, depression could also be a risk factor to influence one's perceived CC. Depression is a significant contributor to the global burden of disease and affects people in all communities across the world. On average about 1 in 20 people reported having an episode of depression in the previous year ${ }^{(12)}$. Within university students population, the prevalence of depression is alarming with an increasing rate irrespective of geographical territory ${ }^{(14)}$. Usually, during the depressive 
period, people show a lack of interest in social interaction thereby distancing themselves from the community they belong to(4).

The existing literature indicates a range of psychological and social factors might influence how close a person feels with his or her community. Although, a handful amount of research has accumulated evidence for the western context, very little is known about Bangladesh. We aimed to understand potential psychosocial factors that might influence one's CC. Revealing these factors would help to design interventions addressing young adults' health and well-being. Further, university/college mental health professionals could explore on the modifiable influencing factors in order for better outcomes in their practice.

\section{Material and Methods}

A total of 300 students was selected purposively from three higher education institutes of Dhaka city serves as study participants. Their age ranges from 18 to 28 years with a mean 22.1 years $(\mathrm{sd}=2.12)$. Detailed information of the study participants is given in Table 1.

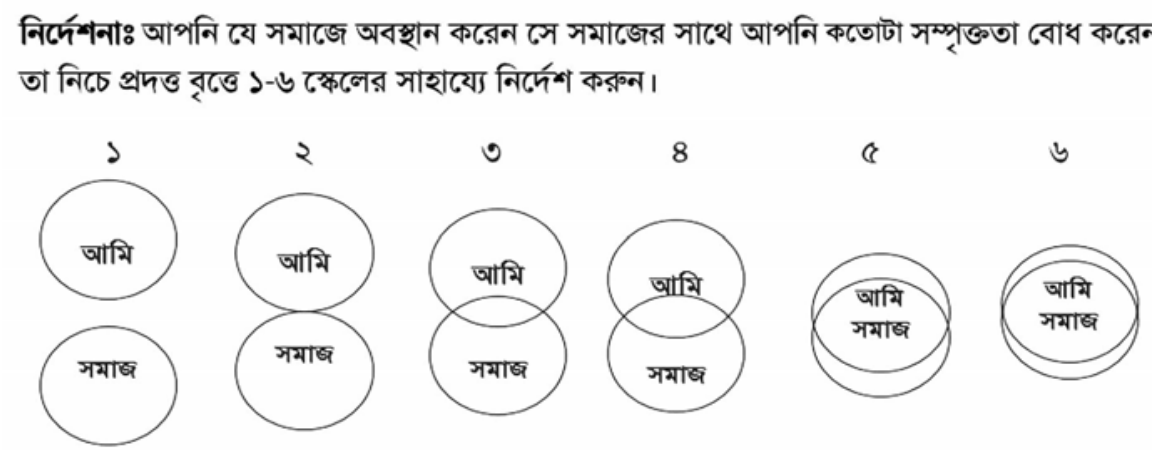

Fig. 1. The inclusion of community in self scale.

Inclusion of community in self (ICS) scale ${ }^{(15)}$ was used to measure the community connectedness. The ICS is a single-item pictorial measure consisting of six pairs of overlapping circles, with each pair of same-size circles overlapping slightly more than the preceding pair (Fig. 1). Scoring of ICS scale is ranging from 1 to 6 where the minimum score is 1 and the maximum score is 6 . The test-retest reliability of the ICS over a two-week period was $\mathrm{r}=0.74$.

The Bangla adapted Internet addiction test (IAT)(16) was used to measure the addictive use of the Internet. The Bangla IAT has 18-items; each item is responded using a 5-point Likert-type scale ranging from 1 (rarely) to 5 (always). The total IAT score is the sum of all items which gives a minimum score of 18 to maximum 90. A higher score indicates a higher level Internet addiction. The Bangla IAT poses sound reliability (Cronbach's alpha 0.89) and discriminant and convergent validity ${ }^{(13,16)}$. 
The depression scale ${ }^{(17)}$ was used to index level of depression. It is a 30 -item selfreport rating scale that measures characteristic attitudes and symptoms of depression. Items are responded on a 5-point Likert-type scale ranging from 1 to 5 . The minimum obtainable score on the scale is 30 and the maximum is 150. A higher score indicates a higher level of depression. In addition, a separate demographic information collection sheet was used to capture information such as sex, age, SES, number of siblings, residential status (residential vs. non-residential), relationship status (yes, no or split), academic orientation (medical, engineering or general university) and academic year (first to fourth year and master's). Ethical approval was obtained from the concerned university ethics committee. Written consent was also obtained from each participant prior to data collection. Participation in this study was voluntary.

\section{Results and Discussion}

Table 1 depicts mean and standard deviations of community connectedness (CC), Internet addiction and depression according to participants' socio-demographic and academic determinants. As seen, there were no statistically significant sex differences in $\mathrm{CC}$ and depression scores. Males, however, scored higher on Internet addiction measure (40.43 vs. 36.71$)$ than their female counterparts $(t=-2.158, p<0.05)$. There were also no significant differences in any of the measures while comparing on the respondents' academic orientation. Academic year, however, did have a significant effect on CC, Internet addiction, and depression. There was a consistent increase of CC from first year Honors to Master level $[\mathrm{F}(4,295)=6.693, \mathrm{p}<0.0001]$. Internet addiction $[\mathrm{F}(4,295)=$ 8.906, $\mathrm{p}<0.0001]$ and depression $[\mathrm{F}(4,295)=8.099, \mathrm{p}<0.0001]$, conversely, decrease as the study year progresses. Residential status was also significantly associated with CC with residential respondents showing higher $\mathrm{CC}$ than the non-residential students $(\mathrm{t}=$ 2.136, $\mathrm{p}<0.05)$. CC was not found to be associated with participants' relationship status. However, having a committed relationship is associated with lower level of depression and Internet addiction.

Table 2 presents bivariate correlations of the key continuous variables. As seen, CC was significantly and positively associated with age, number of siblings and socioeconomic status (SES) indicating higher age, more siblings, and higher SES are linked with higher perceived CC. CC was also significantly and negatively correlated with Internet addiction and depression. The strength of the positive associations was lower while for the negative relations it was higher.

Next, we computed a multiple linear regression with perceived CC as the criterion variable. Age, male gender, number of siblings, non-residential status, SES, Internet addiction and depression were entered simultaneously as predictor variables into the multiple regressions using the standard method. Multi-collinearity diagnostics indicated that this was not a issue (variance inflation factors reported in Table 3). The regression 
Table 1. Mean and standard deviation (in brackets) of the key measures according to sociodemographic and academic variables.

\begin{tabular}{|c|c|c|c|}
\hline & $\begin{array}{l}\text { Community } \\
\text { connectedness }\end{array}$ & $\begin{array}{l}\text { Internet } \\
\text { addiction }\end{array}$ & Depression \\
\hline Total sample $(n=300)$ & $3.64(1.39)$ & $38.57(15.02)$ & $74.31(25.98)$ \\
\hline \multicolumn{4}{|l|}{ Sex } \\
\hline Female $(n=150)$ & $3.60(1.49)$ & $36.71(16.51)$ & $74.40(27.09)$ \\
\hline Male $(n=150)$ & $3.67(1.28)$ & $40.43(13.17)$ & $74.22(24.92)$ \\
\hline \multicolumn{4}{|l|}{ Academic area } \\
\hline Engineering $(n=101)$ & $3.48(1.35)$ & $40.50(14.35)$ & $78.45(23.72)$ \\
\hline Medical $(n=100)$ & $3.80(1.48)$ & $37.61(16.56)$ & $69.79(28.05)$ \\
\hline General $(n=99)$ & $3.63(1.32)$ & 37.59 (13.99) & $74.65(25.54)$ \\
\hline \multicolumn{4}{|l|}{ Academic year } \\
\hline First $(n=25)$ & $2.84(1.52)$ & $51.80(18.93)$ & $95.04(21.67)$ \\
\hline Second $(n=111)$ & $3.40(1.35)$ & $40.00(13.57)$ & $77.25(23.53)$ \\
\hline Third $(\mathrm{n}=47)$ & $3.56(1.46)$ & $39.83(13.08)$ & $74.89(25.92)$ \\
\hline Fourth $(\mathrm{n}=32)$ & $3.75(1.34)$ & $34.69(14.36)$ & $73.16(27.48)$ \\
\hline Master $(\mathrm{n}=85)$ & $4.18(1.22)$ & $33.59(14.26)$ & $64.48(25.75)$ \\
\hline \multicolumn{4}{|l|}{ Residential status } \\
\hline Residential $(\mathrm{n}=174)$ & $3.78(1.39)$ & $37.33(14.81)$ & $71.87(26.58)$ \\
\hline Non-residential $(n=126)$ & $3.44(1.37)$ & $40.29(15.20)$ & $77.67(24.83)$ \\
\hline \multicolumn{4}{|l|}{ Relationship status } \\
\hline In relation $(n=112)$ & $3.63(1.45)$ & $35.20(14.08)$ & $66.18(23.37)$ \\
\hline Single $(n=188)$ & $3.64(1.36)$ & $40.59(15.24)$ & $79.15(26.30)$ \\
\hline
\end{tabular}

Variables highlighted in bold indicate a significant difference in all or any of the measures at 0.05 level.

Table 2. Association of community connectedness with key continuous measures.

\begin{tabular}{llllllll}
\hline & Mean $(\mathrm{sd})$ & 1 & 2 & 3 & 4 & 5 & 6 \\
\hline 1. Community connectedness & $3.64(1.39)$ & 1 & & & & & \\
2. Age & $22.01(2.12)$ & $0.325^{* *}$ & 1 & & & & \\
3. Number of siblings & $2.74(1.43)$ & $0.120^{*}$ & $0.225^{* *}$ & 1 & & & \\
4. Socio-economic status & $6.32(1.84)$ & $0.198^{* *}$ & 0.007 & -0.017 & 1 & & \\
5. Internet addiction & $38.57(15.02)$ & $-0.514^{* *}$ & $-0.265^{* *}$ & 0.056 & -0.101 & 1 & \\
6. Depression & $74.31(25.98)$ & $-0.539^{* *}$ & $-0.267^{* *}$ & -0.095 & $-0.184^{* *}$ & $0.630^{* *}$ & 1 \\
\hline
\end{tabular}

${ }^{*}$ Correlation is significant at the 0.05 level (2-tailed). ${ }^{* *}$ Correlation is significant at the 0.01 level (2-tailed). 
was significant, $\mathrm{F}(7,292)=26.406, \mathrm{p}<.001$, Adj. $\mathrm{R}^{2}=0.373$, with age, SES, Internet addiction and depression emerging as significant predictors. Regression coefficients are reported in Table 3.

Table 3. Standardised and unstandardised regression coefficients for the multiple linear regression with perceived community connectedness as the criterion variable.

\begin{tabular}{lllllll}
\hline Factors & $\mathrm{B}$ & $\mathrm{SE}$ & $\beta$ & $\mathrm{t}$ & $\mathrm{p}$ & $\mathrm{VIF}$ \\
\hline Age & 0.096 & 0.033 & 0.147 & 2.919 & 0.004 & 1.201 \\
Sex & & & & & & \\
Female [ref] & & & & & & \\
Male & 0.140 & 0.132 & 0.050 & 1.056 & 0.292 & 1.083 \\
No. of siblings & 0.067 & 0.047 & 0.068 & 1.428 & 0.154 & 1.094 \\
Residential status & & & & & & \\
Residential [ref] & & & & & & \\
Non-residential & -0.068 & 0.132 & -0.024 & -0.512 & 0.609 & 1.051 \\
Socio-economic status & $\mathbf{0 . 0 9 2}$ & $\mathbf{0 . 0 3 6}$ & $\mathbf{0 . 1 2 2}$ & $\mathbf{2 . 5 9 1}$ & $\mathbf{0 . 0 1 0}$ & $\mathbf{1 . 0 5 8}$ \\
Internet addiction & $\mathbf{- 0 . 0 2 7}$ & $\mathbf{0 . 0 0 6}$ & $\mathbf{- 0 . 2 9 2}$ & $\mathbf{- 4 . 7 4 4}$ & $\mathbf{0 . 0 0 0}$ & $\mathbf{1 . 8 0 4}$ \\
Depression & $\mathbf{- 0 . 0 1 5}$ & $\mathbf{0 . 0 0 3}$ & $\mathbf{- 0 . 2 8 4}$ & $\mathbf{- 4 . 6 4 4}$ & $\mathbf{0 . 0 0 0}$ & $\mathbf{1 . 7 8 8}$ \\
\hline
\end{tabular}

We found that age is positively correlated with CC. The need for belongingness is a basic psychological need for every human being and with physical development, this needs become prominent ${ }^{(18)}$. With aging, individual develop the civic sense and feel the need to participate in civic life ${ }^{(18)}$. This, in turn, helps to reduce social isolation and level of depression. We also observed a significant difference in CC between residential and nonresidential students. Residing in the dormitories with other students open the opportunity to get involve with pro-social activities which again facilitates social connection ${ }^{(19)}$.

In the later investigation of this study, it was found that participant's SES and number of siblings were positively associated with CC. Studies showed that people who are from middle or higher class can maintain a good connection with their community ${ }^{(20)}$. Moreover, siblings serve an important role in each other's lives throughout the life course. Through the sharing of emotions, siblings feel a feeling of connection with the family. Children who have no siblings or have one sibling feel isolated and become stressed in any problem situation ${ }^{(21)}$. On the other hand, who have more siblings they feel more connection among them and can maintain a good bonding with the outer world in the same way ${ }^{(21)}$.

Another significant finding of the study is that CC, depression and Internet addiction is positively linked with each other. Well community connected individual spent more time with the community group and participate in various types of activities. Thus they tend to spent less time in browsing the Internet and become less addicted to it. In 
contrast, less community connected individuals (could be introverted) are likely to engage online social connectivity as a mean of socialization which in turn could lead to compulsive or addictive Internet use. Continuation of this phenomenon in fact facilitates more isolation and a sense of loneliness eventually leading to the development of depressive symptoms ${ }^{(22)}$.

Finally, the study revealed age, SES, Internet addiction and depression as significant predictors influencing CC. Addressing these factors would help students to get connected with the community they belong. However, findings of this study need to be interpreted with caution as it has a number of limitations. For example, the sample was selected only from Dhaka, thereby failing to represent the entire student population of Bangladesh. Additionally, there might be other important determinants behind one's sense of CC. Such as, attachment style of the respondents, genetic factors, cultural and religious values could be potential area for future studies to consider. Nonetheless, the study highlights that health planners and university authorities could take necessary interventions in order to increase CC of students especially targeting determinants including early age, addictive users of the Internet and students suffering from depression.

\section{References}

1. Lee RM, M Draper and S Lee 2001. Social connectedness, dysfunctional interpersonal behaviors and psychological distress : Testing a mediator model. J. Counseling Psychol. 48(3): 310-318.

2. McIntyre E, KKK Wiener and AJ Saliba 2015. Compulsive internet use and relations between social connectedness and introversion. Computers in Human Behavior 48: 569-574.

3. Jampel HD, D Friedman, H Quigley, S Vitale and R Miller 2009. Social Disconnectedness, perceived isolation and health among older adults. J. Health Soc. Behav. 50(1): 41-48.

4. Mehta KM, K Yaffe and KE Covinsky 2002. Cognitive impairment, depressive symptoms, and functional decline in older people. J. American Geriatrics Soc. 50(6): 1045-1050.

5. Putnam RD 1995. Bowling Alone: America's declining social capital. The American of Economic and Sociology 373(6): 3-9.

6. Caetano SC, C Silva and M V Vettore 2013. Gender differences in the association of perceived social support and social network with self-rated health status among older adults: A population-based study in Brazil. BMC Geriatrics 13(122): 1-14.

7. Giummarra MJ, B Haralambous, K Moore and J Nankervis 2007. The concept of health in older age: views of older people and health professionals. Aust. Health Review 31(4): 642-650.

8. Benjamin Cornwell, Edward O. Laumann and LPS 2008. The Social connectedness of older adults: A national profile. Am Social Rev. 73(2): 185-203.

9. Mcmillan DW and DM Chavis 1986. Sense of community: A definition and theory. J. Community Psychol. 14(January): 6-23. 
10. Kim,Kyunghee, R Eunjung, C Mi-Young, E-J Yeun, SY Choi, JS Seod and BW Namd 2006. Internet addiction in Korean adolescents and its relation to depression and suicidal ideation: A questionnaire survey. International Journal of Nursing Studies 43(1): 185-92.

11. Madden M, A Lenhart, M Duggan, S Cortesi and U Gasser 2013. Teens and technology 2013. Washington, DC: Pew Research Center's Internet \& American Life Project 2013: 1-19.

12. World Federation for Mental Health 2012. Depression: A Global Crisis. 2012.

13. Islam MA and MZ Hossin 2016. Prevalence and risk factors of problematic internet use and the associated psychological distress among graduate students of Bangladesh. Asian J. Gambling Issues and Public Health 6(11): 1-14.

14. Sarokhani D, A Delpisheh, Y Veisani, MT Sarokhani, RE Manesh and K Sayehmiri 2013. Prevalence of depression among University students: A systematic review and metaanalysis study. Depression Research and Treatment 2013: 1-7.

15. Mendelson T, AK Turner and SD Tandon 2010. Violence exposure and depressive symptoms among adolescents and young adults disconnected from school and work. J. Community Psychol. 38(5): 607-621.

16. Karim AKMR and N Nigar 2014. The Internet addiction test: Assessing its psychometric properties in Bangladeshi culture. Asian J. Psychiatry 10: 75-83.

17. Uddin MZ and MM Rahman 2005. A scale of depression for use in Bangladesh. Bangladesh Psychological Stud. 15: 25-44.

18. Baumeister RF and MR Leary 1995. The need to belong: Desire for interpersonal attachments as a fundamental human motivation. Psychological Bulletin 117(3): 497.

19. Smith KM, L Cohen and JA Pooley 2003. The relationship between residential satisfaction, sense of community, sense of place, and sense of belonging in a Western Australian urban planned community. Australian J. Psychol. 55: 212.

20. Putnam RD, CB Frederick and K Snellman 2012. Growing class gaps in social connectedness among American youth. The Saguaro Seminar: Civic Engagement in America 1-28.

21. Ferriby MM 2015. Family Separateness' and Connectedness' impact on sibling relationships, stress and depression during emerging adulthood. Electronic Thesis or Dissertation. Ohio State University. https://etd.ohiolink.edu/

22. Galloway AP and M Henry 2014. Relationships between social connectedness and spirituality and depression and perceived health status of rural residents. Online Journal of Rural Nursing and Health Care 14(2): 43-79. 